\begin{tabular}{|l|l|}
\hline JURNAL ABDI MASYA & Volume 1 No 2 \\
& Mei 2021 \\
Ep 108-114 \\
P-ISSN : 2774-2849 $2774-2881$ & Website : https://jurnal.sttw.ac.id/index.php/abma/about \\
\hline
\end{tabular}

\title{
Perancangan Dan Pembuatan Mesin 3D Printer Tipe Cantilever
}

\section{DESIGN AND ASSEMBLY CANTILEVER 3D PRINTER MACHINE}

\author{
Deni Andriyansyah ${ }^{{ }^{*}}$, Sriyanto $^{2}$, Agus Jamaldi ${ }^{3}$ \\ ${ }^{1,2,3}$ Program Studi Teknik Mesin, Sekolah Tinggi Teknologi Warga, Surakarta, Indonesia \\ *E-mail: deni.andriyansyah@sttw.ac.id
}

\begin{abstract}
ABSTRAK
Teknologi 3D printing termasuk dalam metode manufaktu rbaru yang disebut dengan metode additive manufacturing. Metode ini mempunyai cara kerja menumpuk material untuk membuat sebuah objek 3 dimensi. Penelitian dalam bidang desain dan assembly mesin 3D printer masih belum banya kdilakukan. Pada umumnya, mesin-mesin 3D printer yang digunakan memiliki paling tidak 5 motor stepper, yaitu sumbu $X 1$ buah, sumbu $Y 1$ buah, sumbu $Z 2$ buah serta motor ekstruder 1 buah. Paper ini akan membahas mengenai alternative desain mesin $3 D$ printer FFF dengan model cantilever yang menggunakan 4 motor stepper sehingga lebih hemat komponen. Proses desain dan assembly $3 D$ printer tipe cantilever menghasilkan mesin dengan area kerja $200 x$ $200 \times 200 \mathrm{~mm}$ dan ketelitian 0,1 mm. Mesin 3D printer yang didesain memiliki komponen utama berupa komponen mekanik dan elektrik. Komponen mekanik terdiri dari frame, linear guide, bracket, leadscrew, pulley dan timing belt. Komponen elektrik terdiri dari controller, lcd, motor stepper, limit switch, soket serta power supply. Dengan meminimalisir jumlah motor stepper yang digunakan, maka desain 3D printer tipe cantilever dinilai lebih ekonomis dengan desain yang minimalis. Mesin seperti ini cocok digunakan untuk kegiatan-kegiatan yang bersifat mobile. 3D printer ini kedepan akan dimanfaatkan untuk melakukan pelatihan kepada masyarakat untuk memperkenalkan teknologi manufaktur baru, yaitu proses cetak 3 dimensi.
\end{abstract}

Kata Kunci: desain, assembly, 3D printing, cantilever

\begin{abstract}
$3 D$ printing technology is a new manufacturing method called the additive manufacturing method. This method works to stack materials to create a 3-dimensional object. There is not much research in the design and assembly of 3D printer machines. Generally, 3D printer machines used at least 5 stepper motors, 1 for $X$ axis, 1 for $Y$ axis, 2 for $Z$ axis and 1 extruder motor respectively. This paper will discuss the alternative design of a $3 D$ printer FFF machine with a cantilever model that uses 4 stepper motors in order to minimize the amount of components. The design and assembly process of a cantilever type 3D printer produces a machine with awork area of $200 \times 200 \times 200 \mathrm{~mm}$ and an accuracy of $0.1 \mathrm{~mm}$. The main components of a $3 D$ printer machine are mechanical and electrical components. The mechanical components consist of the frame, linear guide, bracket, leadscrew, pulley and timing belt. Electrical components consist of a controller, LCD, stepper motor, limit switch, socket and power supply. By minimizing the number of stepper motors, the cantilever type $3 D$ printer design was considered more economical with a minimalist design. In addition, the machines are suitable for mobile activities such as training for the public. In the future, the $3 D$ printer will be used to introduce new manufacturing technologies, the 3-dimensional printing process.
\end{abstract}

Keywords: design, assembly, 3D printing, cantilever

Submit: 25 April 2021, Revision: 17 Mei 2021, Accepted: 17 Mei 2021 Published: 28 Mei 2021 


\section{PENDAHULUAN}

Teknologi 3D printing termasuk dalam metode manufaktur baru yang disebut dengan metode additive manufacturing. Metode ini mempunyai cara kerja menumpuk material untuk membuat sebuah objek 3 dimensi. Teknologi 3D printing dapat digunakan untuk mencetak objek dengan cepat bahkan pada tahap desain prototype, sehingga biasa disebut juga dengan rapid protoyping [1]. Pada perkembangan selanjutnya, teknologi 3D printing tidak hanya digunakan untuk membuat prototype, namun sudah dapat digunakan untuk membuat objek fungsional [1]. Berbeda dengan proses manufaktur konvensional (substraktif), proses 3D printing tidak menghasilkan material sisa (limbah) dan memiliki komponen yang lebih sederhana sehingga lebih hemat energy [2]. Selainitu, metode additive manufacturing dapat digunakan untuk membuat objek-objek dengan kompleksitas yang tinggi dengan biaya yang relative rendah. Dengan popularitasnya yang semakin berkembang, salah satu metode 3D printing yaitu Fused Filament Fabrication (FFF) diprediksikan akan mencapai pangsa pasar sebesar 2,3 juta dolar AS pada 2022 [3][4].

FFF bekerja dengan melelehkan material filament melalui sebuah ekstruder dan dideposisikan sesuai dengan koordinat objek yang dicetak [5]. Filament yang digunakan dalam FFF pada umumnya terbuat dari Behan termoplastik seperti PLA dan ABS [6]. FFF cukup popular digunakan karena mempunyai desain dan komponen yang sederhana yang sangat cocok untuk mesin-mesin desktop. Selain itu, harga mesin-mesin FFF cukup terjangkau bila dibandingkan dengan mesin 3D printer tipe lain [7].Teknologi 3D printing dapat diaplikasikan pada bidang yang luas seperti aerospace, medis, arsitektur, dan lain-lain [8].

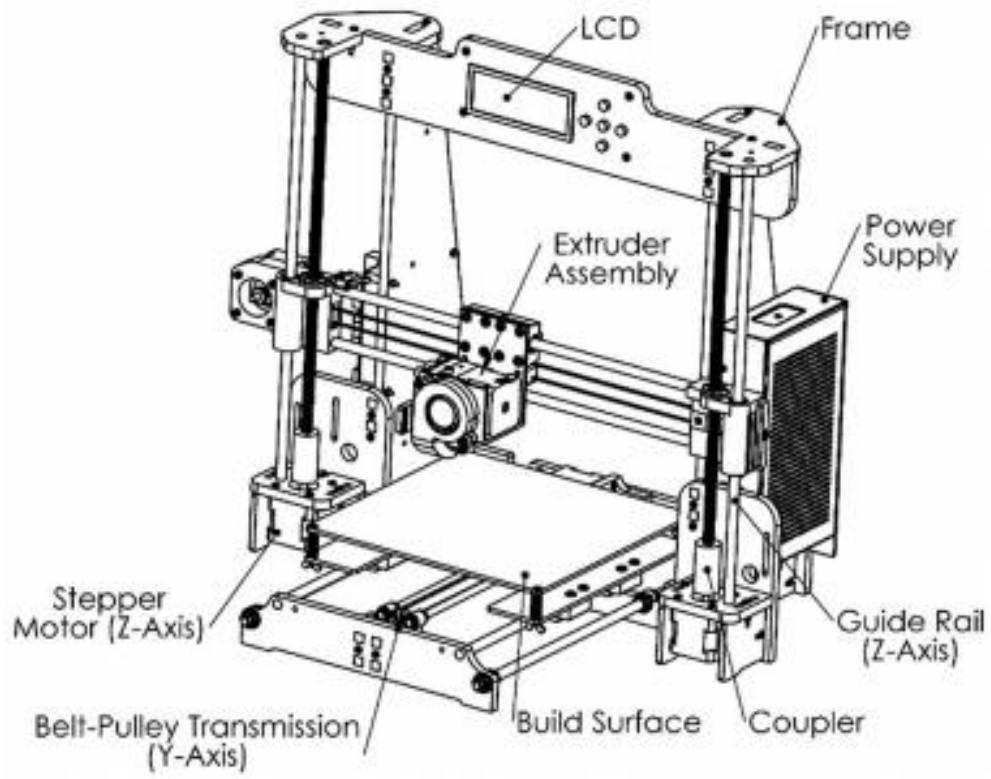

Gambar1. Bagian-bagianmesin 3D printer

Penelitian di bidang 3D printing lebih intens dalam topik peningkatan sifat fisik dan mekanik objek dengan memvariasikan parameter proses 3D printing. Sedangkan penelitian dalam bidang desaindan assembly mesin 3D printer masih belum banyak dilakukan. Pada umumnya, mesin-mesin 3D printer yang digunakan memiliki paling tidak 5 motor stepper, yaitu sumbu X 1 buah, sumbu Y 1 buah, sumbu Z 2 buah serta motor ekstruder 1 buah.Mesin 3D printer jenis ini dapat dilihat padaGambar 1 di atas. Paper ini akan membahas mengenai alternative desain mesin 3D printer FFF dengan model cantilever yang menggunakan 4 motor stepper sehingga lebih hemat komponen. 


\section{METODE}
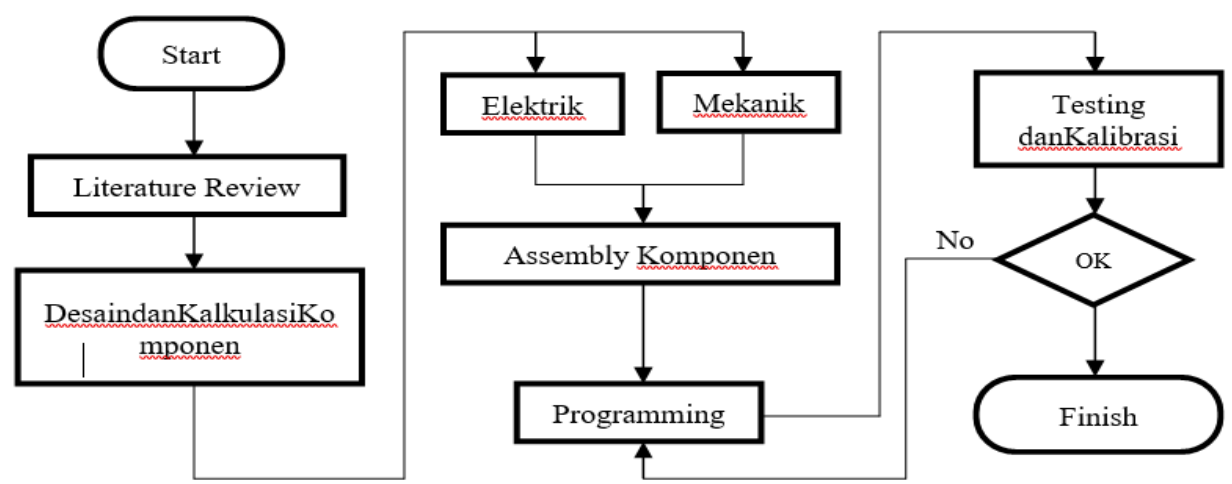

Gambar 2. Diagram alir metode penelitian

Proses perancangan dan pembuatan mesin 3D printer tipe cantilever dilakukan berdasarkan diagram alir pada Gambar 2. Proses ini dimulai dengan mencari referensireferensi mesin yang sudah ada. Mesin-mesin dengan tipe Cartesian mayoritas menggunakan 2 motor stepper pada sumbu Z. Proses desainmesin 3D printer difokuskan untuk menghasilkan rancangan mesin yang hanya menggunakan 1 motor stepper pada sumbu Z. Setelah spesifikasi umum ditentukan, langkah yang selanjutnya adalah proses kalkulasi komponen yang dijabarkan ke dalam dua hal yaitu komponen elektrik dan mekanik. Mesin yang dirancang tetap memanfaatkan komponen-komponen standar yang sering dijumpai pada mesin-mesin 3D printer. Hanya komponen khusus saja yang melalui proses pengerjaan baik menggunakan mesin frais, bubut maupun laser. Langkah berikutnya adalah perakitan komponen menjadi mesin 3D printer yang dilanjutkan dengan proses programming mesin sesuai spesifikasi. Mesin yang dihasilkan mempunyai area kerja standar yaitu 200 x 200 x $200 \mathrm{~mm}$. Selanjutnya mesin diuji reliabilitas dan akurasi dalam mencetak objek. Proses pengujian dilakukan dengan mencetak objek berupa kubus dengan ukuran 20 x 20 x $20 \mathrm{~mm}$. jika objek yang tercetak memiliki dimensi yang sudah sesuai, maka proses perakitan selesai dilakukan. Namun jika ukuran objek belum sesuai, maka akan dilakukan proses kalibrasi pada software maupun hardware.

\section{HASILDANPEMBAHASAN}

\subsection{SpesifikasiMesin}

Mesin 3D printer yang didesain mempunyai spesifikasi dasar yang akan dicapai. Spesifikasi mesin dapat dilihat pada Tabel 1 di bawah.

Tabel 1. Spesifikasi 3D Printer Cantilever

\begin{tabular}{cc}
\hline Item & Keterangan \\
\hline KecepatanCetak & $10-100 \mathrm{~mm} / \mathrm{s}$ \\
Frame & Aluminiumekstrusi $2020 \mathrm{mix} 2040$ \\
Area Kerja & $200 \times 200 \times 200 \mathrm{~mm}$ \\
Motor & $4 \times$ Nema 17 Stepper Motor \\
Diameter Nozzle & $0,4 \mathrm{~mm}$ \\
Temperatur Hot End & $0-250^{\circ} \mathrm{C}$ \\
Temperatur Heat Bed & $0-100^{\circ} \mathrm{C}$ \\
Support Filament Diameter & $1,75 \mathrm{~mm}$ \\
Firmware & Marlin \\
Konektifitas & SD Card \\
Power & 360 Watt max \\
DimensiMesin & $400 \times 400 \times 400 \mathrm{~mm}$ \\
BeratMesin & $10 \mathrm{Kg}$ \\
\hline
\end{tabular}

DOI: https://doi.org/10.52561/abma.v1i2.139 


\subsection{Mekanisme Penggerak}

Dalam perancangan mesin 3D printer, mekanisme penggerak yang biasa digunakan diantaranya linear guide, linear shaft dan $\mathrm{v}$ wheel.Mekanisme ini dipadu dengan transmisi berupa leadscrew dan timing belt. 3D printer yang didesain dalam penelitian ini memanfaatkan mekanisme penggerak berupa kombinasi linear guide dan timing belt pada sumbu Y, $v$ wheel dan timing belt untuk sumbu X serta $\mathrm{v}$ wheel dan leadscrew pada sumbu Z. Mekanisme ini dapat dilihat pada Gambar 3 di bawah.

(a)

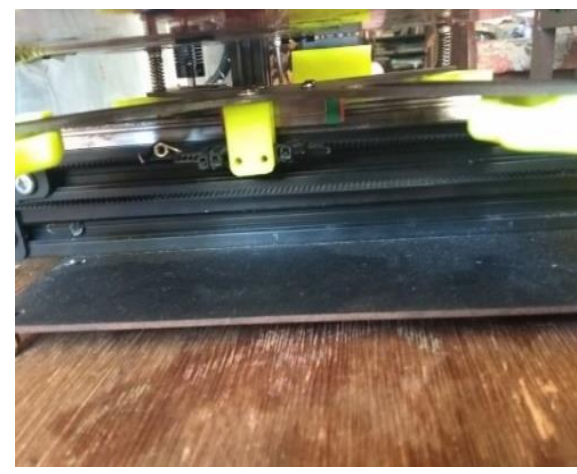

(b)

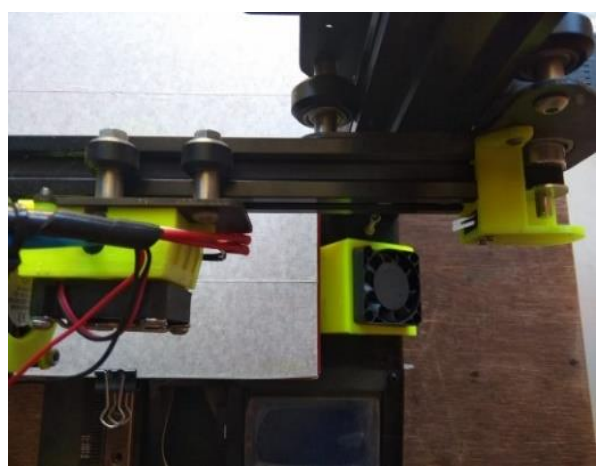

(c)

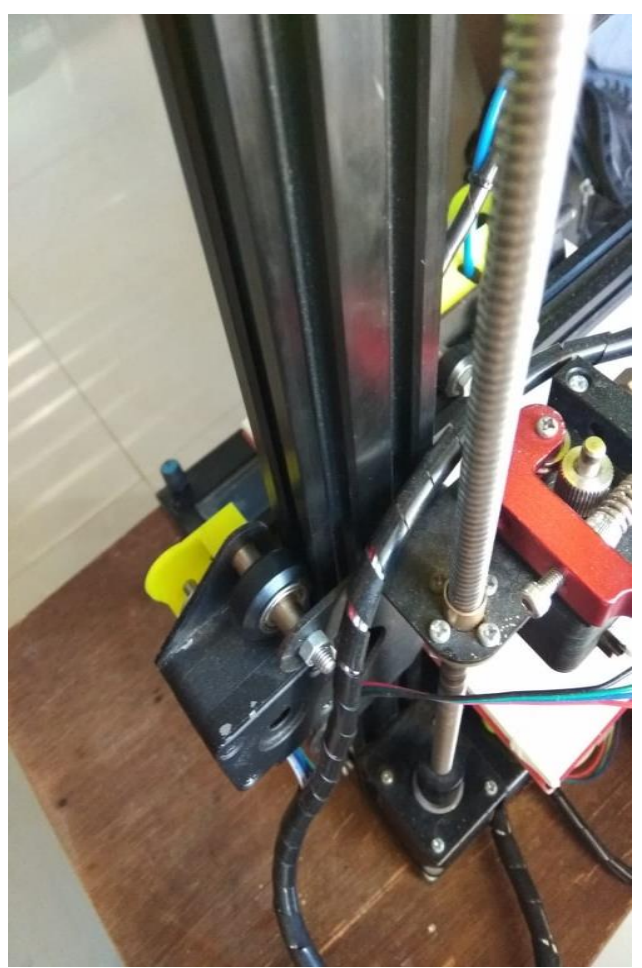

Gambar 3. Mekanisme penggerak (a) Sumbu Y, (b) Sumbu X dan (c) Sumbu Z

\subsection{Desain dan Assembly 3D Printer}

Mesin 3D printer yang didesain memiliki komponen utama berupa komponen mekanik dan elektrik. Komponen mekanik terdiri dari frame, linear guide, bracket, leadscrew, pulley dan timing belt.Komponen elektrik terdiri dari controller, lcd, motor stepper, limit switch, soket serta power supply. Desain mesin 3D printer dapat dilihat pada Gambar 3 di bawah. 


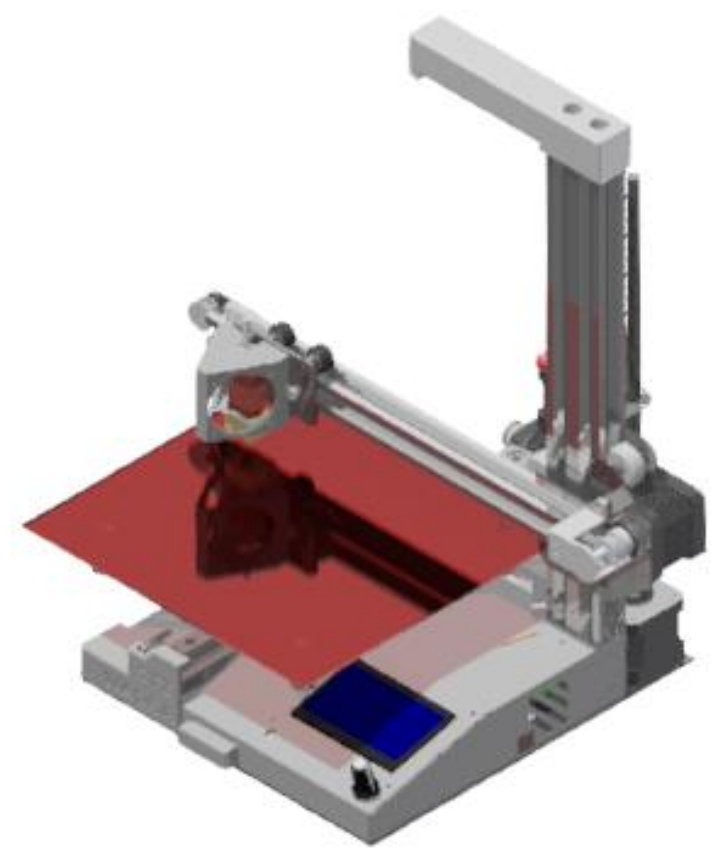

Gambar 3. Desain mesin 3D printer

Desain yang telah dibuat kemudian direalisasikan dalam bentuk mesin yang sebenarnya. 3D printer tipe cantilever mengeleminasi jumlah motor stepper yang digunakan pada sumbu $\mathrm{Z}$ seperti tampak pada Gambar 4. Ekstruder tipe Bowden digunakan untuk mengurangi beban pada sumbu X, sehingga pergerakan sumbu X lebih stabil dan gerakan ekstruder dapat lebih cepat. Posisis LCD controller ditempatkan di sebelah kanan untuk memudahkan aksesibilitas dalam pengoperasian.

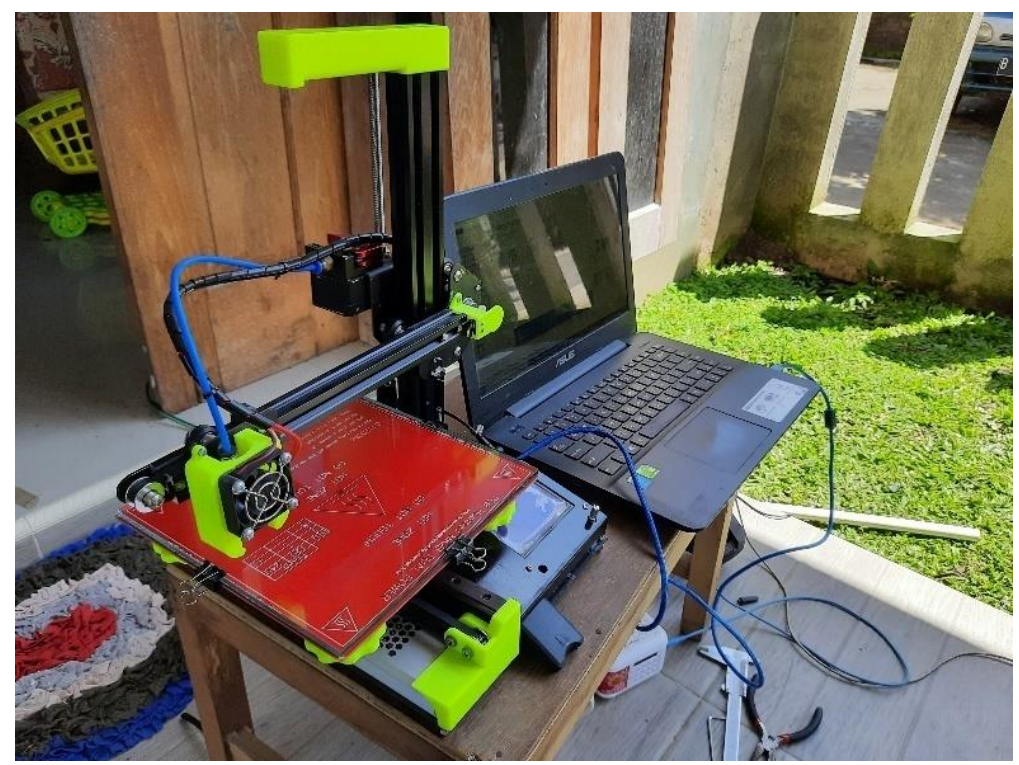

Gambar 4. Assembly mesin 3D printer

\subsection{Kalibrasi}

3D printer yang sudah dirakit kemudian diujicoba untuk mengetahui performa mesin. Kalibrasi steps/mm digunakan untuk menentukan akurasi gerakan tiap sumbu mesin dan ekstruder. Rumus kalibrasi ditentukan sebagai berikut : 
Keterangan:

Distance yang digunakan pada kalibrasi sumbu merupakan pergerakan linier sumbu masingmasing, sedangkan pada ekstruder digunakan filament sebagai bantuan untuk mengetahui berapa pergerakan ekstruder.

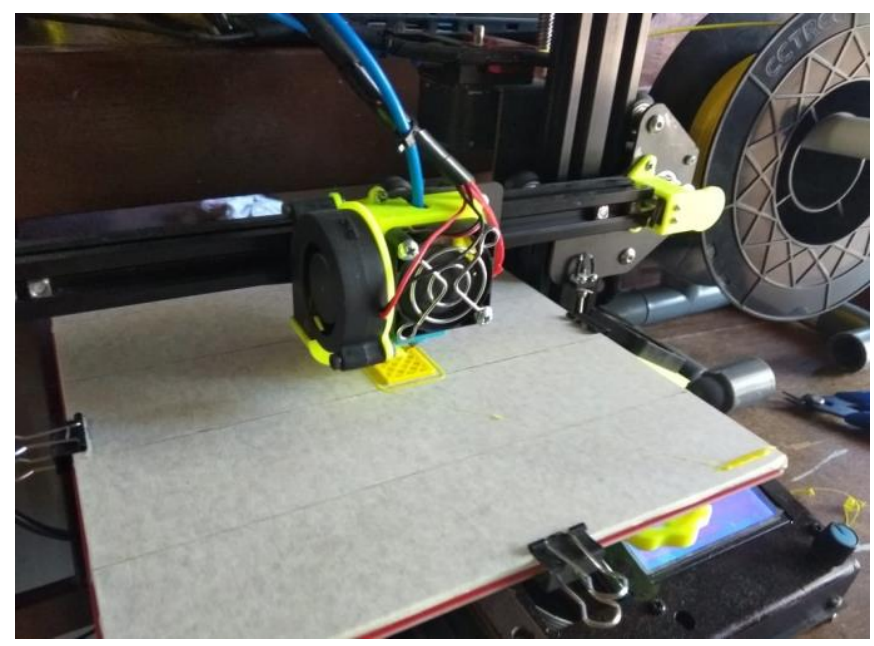

Gambar 5. Proses pencetakan kubuskalibrator

Setelah kalibrasi steps/mm selesai dilakukan, langkah selanjutnya adalah kalibrasi objek hasil 3D printing. Proses kalibrasi dilakukan dengan mencetak kubus kalibrator dengan ukuran 20 × 20 × $20 \mathrm{~mm}$ seperti tampak pada Gambar 5. Hasil pengukuran menunjukkan bahwa dimensi kubus kalibrator sudah sesuai sehingga mesin sudah dapat digunakan untuk mencetak objek-objek 3 dimensi. Kubus hasil kalibrasi dapat dilihat pada Gambar 6.

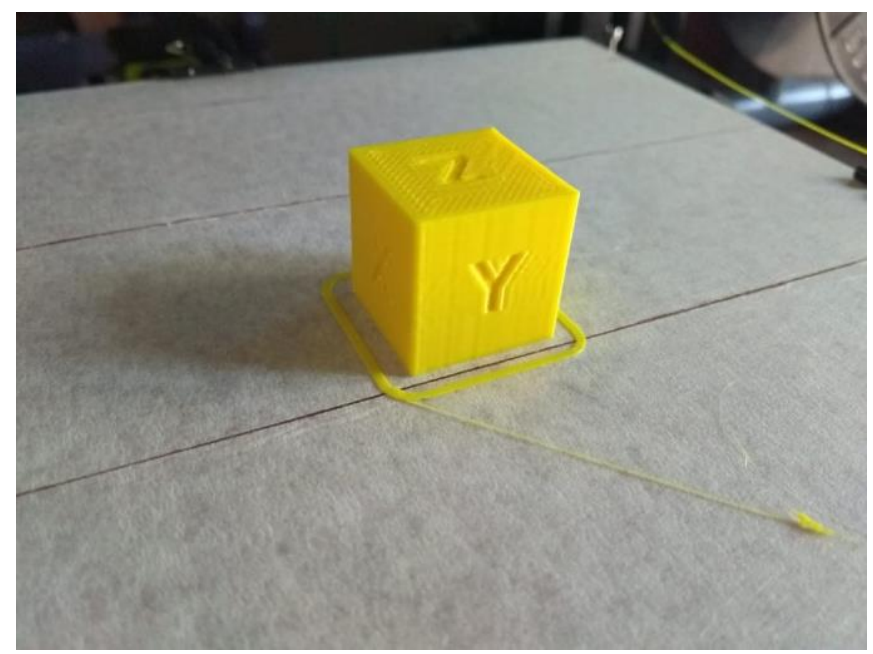

Gambar 6. Kubus kalibrator

\section{KESIMPULAN}

Proses desain dan assembly 3D printer tipe cantilever menghasilkan mesin dengan area kerja $200 \times 200 \times 200 \mathrm{~mm}$ dan ketelitian $0,1 \mathrm{~mm}$. Mesin 3D printer yang didesain memiliki komponen utama berupa komponen mekanik dan elektrik. Komponen mekanik terdiri dari frame, linear guide, bracket, leadscrew, pulley dan timing belt. Komponen elektrik terdiri dari controller, lcd, motor stepper, limit switch, soketserta power supply. Dengan 
meminimalisir jumlah motor stepper yang digunakan, maka desain 3D printer tipe cantilever dinilai lebih ekonomis dengan desain yang minimalis. Mesin seperti ini cocok digunakan untuk kegiatan-kegiatan yang bersifat mobile. 3D printer ini kedepan akan dimanfaatkan untuk melakukan pelatihan kepada masyarakat untuk memperkenalkan teknologi manufaktur baru, yaitu proses cetak 3 dimensi.

\section{UCAPANTERIMAKASIH}

Proses desain dan assembly 3D printer tipe cantilever ini didukung melalui pendanaan Program Penelitian dan Pengabdian Lokal STT Warga Surakarta. Peneliti menyampaikan ucapan terimakasih kepada Ketua STT Warga, Ketua LPPM dan semua pihak yang membantu terwujudnya program ini.

\section{DAFTAR PUSTAKA}

[1] H.I. Medellin-Castillo, J. Zaragoza-Siqueiros, "Design and Manufacturing Strategies for Fused Deposition Modelling in Additive Manufacturing: A Review," Chin J. Mech. Eng.,vol. 32, December 2019.

[2] J. Faludi, C. Bayley, S. Bhogal, M. Iribarne, "Comparing Environmental Impacts of Additive Manufacturing vs. Traditional Machining via Life-Cycle Assessment," Rapid Prototyping. J.,vol21, pp. 14-33, January 2015.

[3] J. Shah, B. Snider, T. Clarke, S. Kozutsky, M. Lacki, A. Hosseini, "Large-scale 3D printers for additive manufacturing: design considerations and challenges," Int. J. Adv. Manuf. Technology, vol. 104, pp. 1-15, October 2019.

[4] 3D Printing Global Market Size, Share, Trend \& Research Report (2015). https://www.bccresearch.com/market-research/instrumentation-andsensors/globalmarkets-for-3d-printing.html. Accessed 8 Aug 2020

[5] M. Taufik, P.K. Jain, "Computer Aided Visualization Tool for Part Quality Analysis of Additive Manufacturing Process, ”in: Proc. ASME Des. Eng. Tech. Conf., August 21-24, 2016.

[6] A. Paolini, S. Kollmannsberger, E. Rank, "Additive manufacturing in construction: A review on processes, applications, and digital planning methods," Addit. Manuf., vol. 30, December 2019.

[7] N. Kumar, P.K. Jain, P. Tandon, P.M. Pandey, "Analysing the influence of raster angle, layer thickness and infill rate on the compressive behaviour of EVA through CNC-assisted fused layer modelling process," J. Brazilian Soc. Mech. Sci. Eng.,vol. 40 (2018).

[8] T. D. Ngo, A. Kashani, G. Imbalzano, K. T. Q. Nguyen, D. Hui, "Additive Manufacturing (3D Printing): A Review of Materials, Methods, Applications and Challenges," Composites Part B, vol. 143, pp. 172-196, February 2018.

[9] How to Calibrate Your Extruder

(2015).

https://www.matterhackers.com/articles/how-to-calibrate-yourextruder\#: :text=The $\% 20$ formula $\% 20$ is $\% 20$ simple $\% 3 \mathrm{~A}$,measured $\% 20$ distance $\% 2$ 0filament\%20traveled)\%5D.Accessed 22 April 2021. 